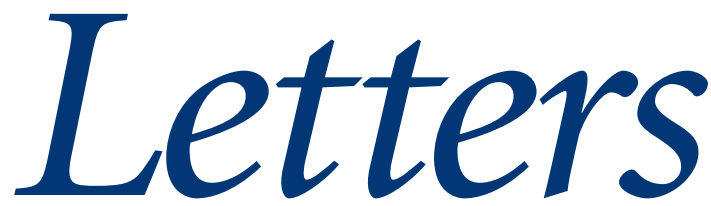

All letters are subject to editing and may be shortened. Letters should be sent to the BJGP office by e-mail in the first instance, addressed to

journal@rcgp.org.uk (please include your postal address). Alternatively, they may be sent by post as an MS Word or plain text version on CD or DVD. We regret that we cannot notify authors regarding publication. Letters not published in the Journal may be posted online on our Discussion Forum. For instructions please visit: http://www.rcgp.org.uk/bjgp-discuss

\section{Children's Commissioner}

I write in great appreciation of the article by Dr Jane H Roberts on Poverty, Violence and Child Protection in the BJGP. ${ }^{1}$

However, despite the excellence of the contribution, there appears to be one error - it is incorrect to assert the Sir Al Aynsley-Green is the UK's first Children's Commissioner. Professor Al AynsleyGreen was appointed in March 2005, whereas the UK's first Children's Commissioner was, in fact, the late Peter Clarke, Children's Commissioner for Wales, appointed on 1 March 2001.

\section{David R Lloyd}

National Assembly for Wales, Cardiff Bay, Cardiff. E-mail: dai.Iloyd@wales.gsi.gov.uk

\section{REFERENCE}

1. Roberts JH. Poverty, violence, and child protection. Br J Gen Pract 2008; 58(554): 658-659.

\section{Managing hyperglycaemia}

Drs Munro and Feher provide an interesting, useful overview of glucose metabolism and emerging therapies for managing hyperglycaemia in their recent editorial. ${ }^{1}$ However, the elephant in the room they fail to discuss is this: in an asymptomatic patient, how clinically worthwhile is reducing a surrogate marker such as HbAlc?

They state that the recent ACCORD and ADVANCE studies 'show microvascular benefit' from intensive glucose reduction and conclude that 'glucose lowering in type 2 diabetes continues to show clear benefits'. But, just what are these benefits? The ACCORD $^{2}$ study did not report microvascular endpoints and the primary outcome of death and major cardiovascular events (which, may be argued, is of greater interest to patients than their $\mathrm{HbA1c}$ level) was greater in the intensive glucose group. The ADVANCE $^{3}$ study does indeed show benefit, but Munro and Feher do not provide the absolute figures with which we can help our patients make informed decisions. This high-quality, large $(\mathrm{n}=$ 11140 ) study showed that over a median of 5 years, intensive glucose control reduced the incidence of combined major macrovascular and microvascular events from $20 \%$ to $18.1 \%$. We should say to our patients that this recent evidence shows that intensive glucose lowering over 5 years will reduce their risk of a significant event by $1.9 \%$ and let them decide. Most mortality in type 2 diabetes is cardiovascular, and an associated editorial makes it clear that on 'the fundamental question of the effect of glycaemic control on macrovascular complications there should be no misunderstanding that the ADVANCE trial had clearly negative results'. ${ }^{4}$ These results seem to echo the UKPDS study, for which commentators have pointed out that results are over-hyped and the evidence of benefit in terms of glycaemic control are, at best, very modest $(2.4 \%$ absolute reduction in microvascular complications over 10 years, and a clinically important reduction in macrovascular events and mortality only seen with metformin and seemingly independent of its glucoselowering effect). ${ }^{5}$

The authors' appraisal of these new drugs is more positive than a recent DTB paper. ${ }^{6}$ The bottom-line of the independent review by the DTB is that, on the basis of the evidence we have, they cannot recommend their routine use but exenatide may prove to be a useful alternative to insulin in some patients. Previous hype around glitazones and inhaled insulin may have made us cynical, but to quote the $N$ Eng $J$ Med again 'we don't need lots of new drugs for diabetes, we just need to use the ones we already have effectively'. ${ }^{7}$ I am confident that Munro and Feher do not have any conflicts of interest which may influence their opinion, but it would be nice if the BJGP reassured readers by making this explicit, as is common practice in other journals.

\section{Simon Curtis}

Hot Topics Course Director, NB Medical Education.E-mail: scurtis@nbmedical.co.uk

\section{REFERENCES}

1. Munro N, Feher MD. Current, new, and emerging therapies for managing hyperglycaemia in type 2 diabetes. Br J Gen Pract 2008; 58(553): 531-533.

2. Action to Control Cardiovascular Risk in Diabetes Study Group. Effects of intensive glucose lowering in type 2 diabetes. N Eng J Med 2008; 358(24): 2545-2559.

3. ADVANCE Collaborative Group. Intensive blood glucose control and vascular outcomes in patients with type 2 diabetes. N Eng J Med 2008; 358(24): 2560-2572.

4. Cefalu WT. Glycemic targets and cardiovascular disease. N Eng J Med 2008; 358(24): 2633-2635.

5. McCormack J, Greenhalgh T. Seeing what you want to see in randomised controlled trials: versions and perversions of UKPDS data. United Kingdom prospective diabetes study. BMJ 2000; 320(7251): $1720-1723$.

6. Anonymous. Three new drugs for type 2 diabetes. Drug Ther Bull 2008; 46(7): 49-52.

7. Nathan DM. Finding new treatments for diabetes how many, how fast... how good? N Eng J Med 2007: 356(5): 437-440.

DOI: 10.3399/bjgp08X342408

\section{Authors' response}

We are surprised to see that the letter by Dr Curtis is published as a critique of 